\title{
Influence of Threshold Chloride Concentration on Corrosion Behavior of Low-Alloy Steel Rebar in Concrete Pore Solutions
}

\author{
Ziyi Zhang* \\ School of Civil and Construction Engineering, Oregon State University, Kearney Hall, 1491 SW \\ Campus Way, Corvallis, OR 97331 \\ *E-mail: zhangziyitg@ sina.com
}

doi: $10.20964 / 2020.10 .20$

Received: 19 May 2020 / Accepted: 16 July 2020 / Published: 31 August 2020

\begin{abstract}
Corrosion of steel reinforced concrete by the chloride-induced is the most common types of degradation in the building and construction industry. Here, the corrosion behavior of Chromium (Cr)modified low-carbon and low-alloy steel rebars exposed to simulated concrete pore solution (SCPS) with different chloride content were studied by the electrochemical impedance spectroscopy (EIS) technique. EIS results indicate that Cr-modified low-alloy steel reveal a higher corrosion protection with a high level of threshold chloride in SCPS and higher impedance than the low-carbon steel. The double-layer capacitance values were reduced as $\mathrm{pH}$ value gradually increased, which indicates that the thickness of the passive layer was enhanced, resulting in an increase in the protective capacity. Scanning electron microscopy investigation confirmed the results attained by EIS measurement. The findings show that low-alloy steel indicates higher resistance of pitting corrosion because of the formation of Cr-enriched stable and protective rust layer.
\end{abstract}

Keywords: Threshold chloride level; Low-alloy steel rebar; Simulated concrete pore solution; Electrochemical impedance spectroscopy

\section{FULL TEXT}

(C) 2020 The Authors. Published by ESG (www.electrochemsci.org). This article is an open access article distributed under the terms and conditions of the Creative Commons Attribution license (http://creativecommons.org/licenses/by/4.0/). 